\title{
Optimasi Fungsi Keanggotaan FIS Tsukamoto Menggunakan Simulated Annealing Untuk Identifikasi Penyakit Gigi
}

\author{
Triando Hamonangan Saragih , Rahmat Ramadhani, Muhammad Itqan Mazdadi , \\ Ahmad Rusadi Arrahimi , Mohammad Reza Faisal \\ Program Studi Ilmu Komputer, Fakultas Matematika dan Ilmu Pengetahuan Alam, \\ Universitas Lambung Mangkurat \\ Jl. A. Yani KM 36, Kota Banjarbaru, Kalimantan Selatan, Indonesia 70714 \\ email: triando.saragih@ulm.ac.id
}

\begin{abstract}
Teeth are one of the tools in the framework related to the human stomach which fills as a food destroyer for simple processing. Diseases that attack teeth can withstand this action and cannot be distinguished quickly by young dental specialists. This problem can be solved by methods in the field of technology. The algorithm that can be used is FIS Tsukamoto in classification. Optimization of the membership function at FIS Tsukamoto is needed to improve accuracy. Optimization of FIS Tsukamoto membership function using Simulated Annealing produced the highest accuracy at 92.5\% of the 100 test data.
\end{abstract}

Keywords: Simulated Annealing; FIS Tsukamoto, Dental Disease, Optimization

Abstrak

Gigi adalah salah satu alat dalam kerangka terkait perut manusia yang mengisi sebagai penghancur makanan untuk pemrosesan sederhana. Penyakit yang menyerang gigi dapat menahan tindakan ini dan tidak dapat dibedakan dengan cepat oleh dokter muda spesialis gigi. Masalah ini dapat diselesaikan dengan metode di bidang teknologi. Algoritma yang bisa digunakan yaitu FIS Tsukamoto dalam melakukan klasifikasi. Optimasi fungsi keanggotaan pada FIS Tsukamoto diperlukan untuk meningkatkan akurasi. Optimasi fungsi keanggotaan FIS Tsukamoto menggunakan Simulated Annealing menghasilkan akurasi paling tinggi yaitu 92,5\% dari 100 data uji.

Kata kunci: Simulated Annealing; FIS Tsukamoto, Penyakit Gigi, Optimisasi 


\section{PENDAHULUAN}

Gigi merupakan salah satu alat pencernaan pada manusia. Gigi mempunyai pengaruh besar dalam menghancurkan makanan yang masuk ke dalam mulut agar makanan mudah untuk dicerna. Banyaknya penyakit yang menyerang gigi dapat mengganggu proses ini.

Berkembang pesatnya teknologi di bidang kedokteran dapat membantu menyelesaikan permasalahan penyakit gigi. Kehadiran teknologi dalam menyelesaikan masalah ini bukan sebagai pengganti dokter gigi yang ada, melainkan sebagai pelengkap untuk membantu dokter gigi atau mahasiswa kedokteran gigi untuk menganalisis penyakit gigi yang menyerang seseorang.

Beberapa metode dapat memecahkan masalah ini, tetapi hanya sedikit metode yang sebelumnya telah diteliti, seperti menggunakan fuzzy. Beberapa fuzzy dapat menyelesaikan masalah yang ada, seperti FIS Tsukamoto[1], FIS Mamdani [2], Fuzzy AHP [3], dan Fuzzy KNN [4], Fuzzy diyakini menjadi salah satu solusi yang baik untuk menyelesaikan masalah ini.

Dalam penelitian sebelumnya menggunakan FIS menghasilkan 70\% untuk identifikasi kasus penyakit gigi [5], Masalah subyektif dari fungsi keanggotaan dokter menjadi masalah lain. Metode optimasi dapat menjadi solusi untuk mengatasi masalah subjektivitas fungsi keanggotaan dokter. Penelitian yang telah dilakukan dengan hibridisasi menggunakan strategi evolusi dalam logika fuzzy menghasilkan akurasi 82\% untuk kasus-kasus identifikasi penyakit gigi [6].

Metode optimasi sangat berkontribusi untuk memberikan solusi yang lebih baik. Algoritma Genetika adalah salah satu metode optimasi yang menggunakan prinsip evolusi. Berdasarkan penelitian sebelumnya yang dilakukan oleh Priyono dan Surendro [1] menggunakan FIS Tsukamoto untuk rekomendasi kebutuhan nutrisi. Dalam penelitian ini, dapat disimpulkan bahwa penggunaan metode FIS Tsukamoto efektif dalam menentukan rekomendasi kebutuhan gizi.

Penelitian lain menggunakan FIS Mamdani yang dioptimalkan untuk prediksi tentang seberapa utuh sebuah batu dan batu anisotropik dari batu oleh Asadi [2], Dalam penelitian ini Asadi mengoptimalkan fungsi keanggotaan fuzzy dan kemudian membuat prediksi menggunakan FIS Mamdani. Hasil penelitian ini adalah memiliki RSME untuk integritas batu 9,57 dan RSME untuk massa anisotropik batu 5,59.

Studi lain yang dilakukan oleh Galankashi, Helmi dan Hashemzahi [3] adalah pemilihan pemasok menggunakan kombinasi Balanced Scorecard dan metode Fuzzy AHP. Kesimpulan dari penelitian ini adalah bahwa menggabungkan kedua metode ini dapat dilakukan, tetapi harus ada penelitian lebih lanjut untuk mengembangkan penggabungan kedua metode ini atau menggabungkan Balanced Scorecard dengan metode lain untuk mendapatkan hasil yang lebih baik.

Penelitian lain menggunakan Fuzzy KNN dengan menggabungkan metode Principal Component Analysis (PCA) dengan Artificial Immune Recognition System (AIRS) untuk diagnosis aterosklerosis berdasarkan Sinyal Doppler di Head Vessels 
[4]. Penelitian ini memberikan hasil akurasi 100\% dengan menggabungkan ketiga metode ini tetapi memiliki waktu komputasi yang sangat lama.

Keberadaan penelitian sebelumnya dengan objek yang sama membuat penulis mengambil FIS Tsukamoto sebagai metode. Simulated Annealing diambil sebagai optimisasi fungsi keanggotaan fuzzy untuk meningkatkan hasil akurasi. Berdasarkan penelitian sebelumnya oleh Fajri et al [7], Simulated Annealing mampu meningkatkan hasil akurasi dengan mengoptimasi fungsi keanggotaan. Oleh karena itu penulis mengambil topik fungsi penelitian optimasi keanggotaan fuzzy menggunakan Simulated Annealing pada identifikasi penyakit gigi menggunakan FIS Tsukamoto.

\section{METODOLOGI PENELITIAN}

\subsection{FIS Tsukamoto}

Fuzzy Tsukamoto telah banyak digunakan sebagai metode penentuan keputusan atau prediksi dalam penelitian sebelumnya. Metode ini memiliki aturan yang mengandung IF-THEN. Setiap aturan memiliki nilai alpha predikat dan predikat yang nantinya akan digunakan sebagai perhitungan nilai akhir FIS Tsukamoto sebagai pengambil keputusan [1].

Data basis aturan berdasarkan Tabel 1 diperoleh berdasarkan konsultasi dengan para ahli dari kedokteran gigi. Aturan dasar ini berasal dari beberapa kasus yang sering terjadi dalam kehidupan nyata. Kasus yang sering disederhanakan menjadi beberapa gejala yang mungkin. Berikut adalah fungsi keanggotaan dari setiap gejala dan penyakit yang ada.

Kategori level pada gejala penyakit gigi dijabarkan sebagai berikut:

A: Rendah

B: Sedang

C: Tinggi

Sedangkan kategori pada penyakit gigi dijabarkan sebagai berikut

1: Pulpitis

2: Gingvitis

3: Periodontitis

4: Periodontitis Akut

Tabel 1. Spesifikasi peralatan

\begin{tabular}{ccccccccc}
\hline Aturan & Plak & $\begin{array}{c}\text { Radang } \\
\text { Gusi }\end{array}$ & Nyeri & $\begin{array}{c}\text { Gusi } \\
\text { Memerah }\end{array}$ & $\begin{array}{c}\text { Gusi } \\
\text { Bengkak }\end{array}$ & $\begin{array}{c}\text { Gusi } \\
\text { Berdarah }\end{array}$ & $\begin{array}{c}\text { Bau } \\
\text { Mulut }\end{array}$ & $\begin{array}{c}\text { Gigi } \\
\text { Goyah }\end{array}$ \\
\hline 1 & A & A & A & & & & & \\
2 & A & A & B & & & & & \\
3 & A & A & B & & & & & \\
4 & A & A & C & & & & & \\
5 & A & A & C & & & & & \\
6 & A & B & A & & & & & \\
\hline
\end{tabular}




\begin{tabular}{cccc}
7 & A & B & B \\
8 & A & B & B \\
9 & B & B & B \\
10 & B & B & B \\
11 & B & B & B \\
12 & B & B & B \\
13 & B & B & B \\
14 & B & C & B \\
15 & B & C & B \\
16 & B & C & C \\
17 & C & C & C \\
18 & C & C & C \\
19 & C & C & C \\
20 & C & C & C \\
21 & C & C & C \\
22 & C & C & C \\
\hline
\end{tabular}

Dalam Gambar 2 adalah fungsi keanggotaan dari semua gejala penyakit gigi. Ada delapan gejala yang digunakan untuk identifikasi penyakit. Definisi fungsi keanggotaan dapat dilihat pada persamaan (1), (2) dan (3).

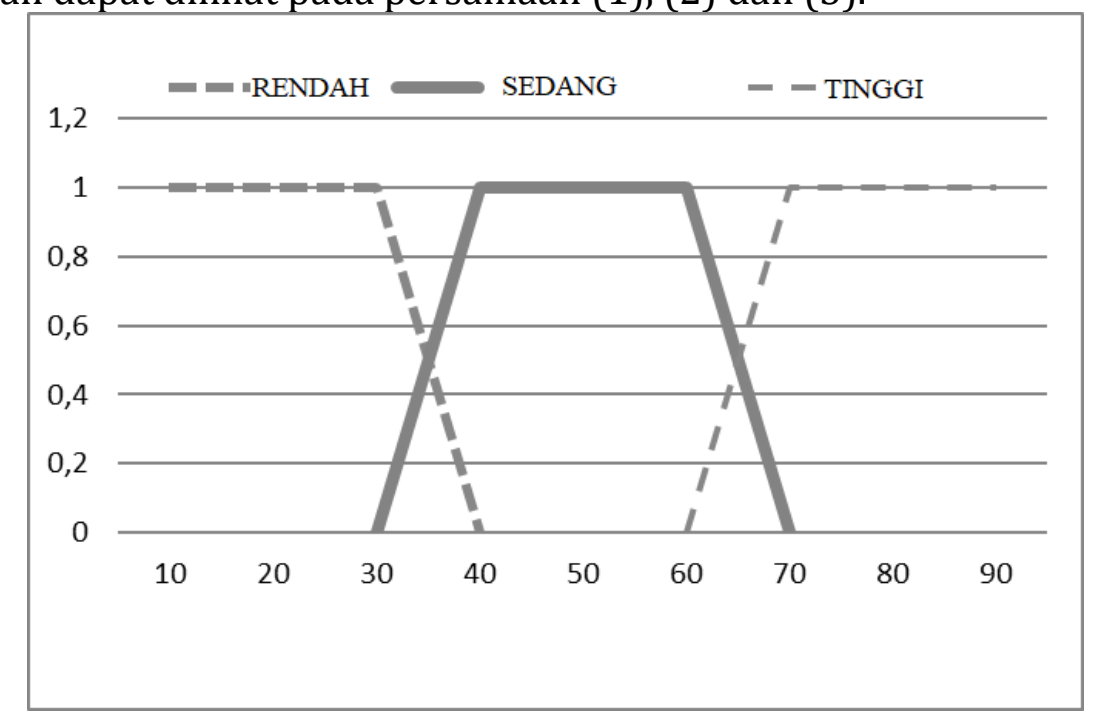

\section{Gambar 1. Fungsi Keanggotaan Gejala}

$\mu_{\text {Rendal }}(x)=\left\{\begin{array}{cc}0 ; & x \geq 40 \\ \frac{40-x}{40-a 0} ; & 30<x<40 \\ 1 ; & x \leq 30\end{array}\right.$

$\mu$ SEDANG $(x)=\left\{\begin{array}{c}0 ; x \leq 30, x \geq 70 \\ \frac{x-30}{40-30} ; 30 \leq x \leq 40 \\ \frac{70-x}{70-60} ; \quad 60 \leq x \leq 70 \\ 1 ; \quad 40 \leq x \leq 60\end{array}\right.$ 
$\mu_{\text {Tinggi }}(x)=\left\{\begin{array}{cc}1_{s}^{*}, & x \geq 70 \\ \frac{x-60}{70-60} ; & 60<x<70 \\ 0 ; & x \leq 60\end{array}\right.$

Fungsi keanggotaan penyakit gigi dapat dilihat pada Gambar 2.

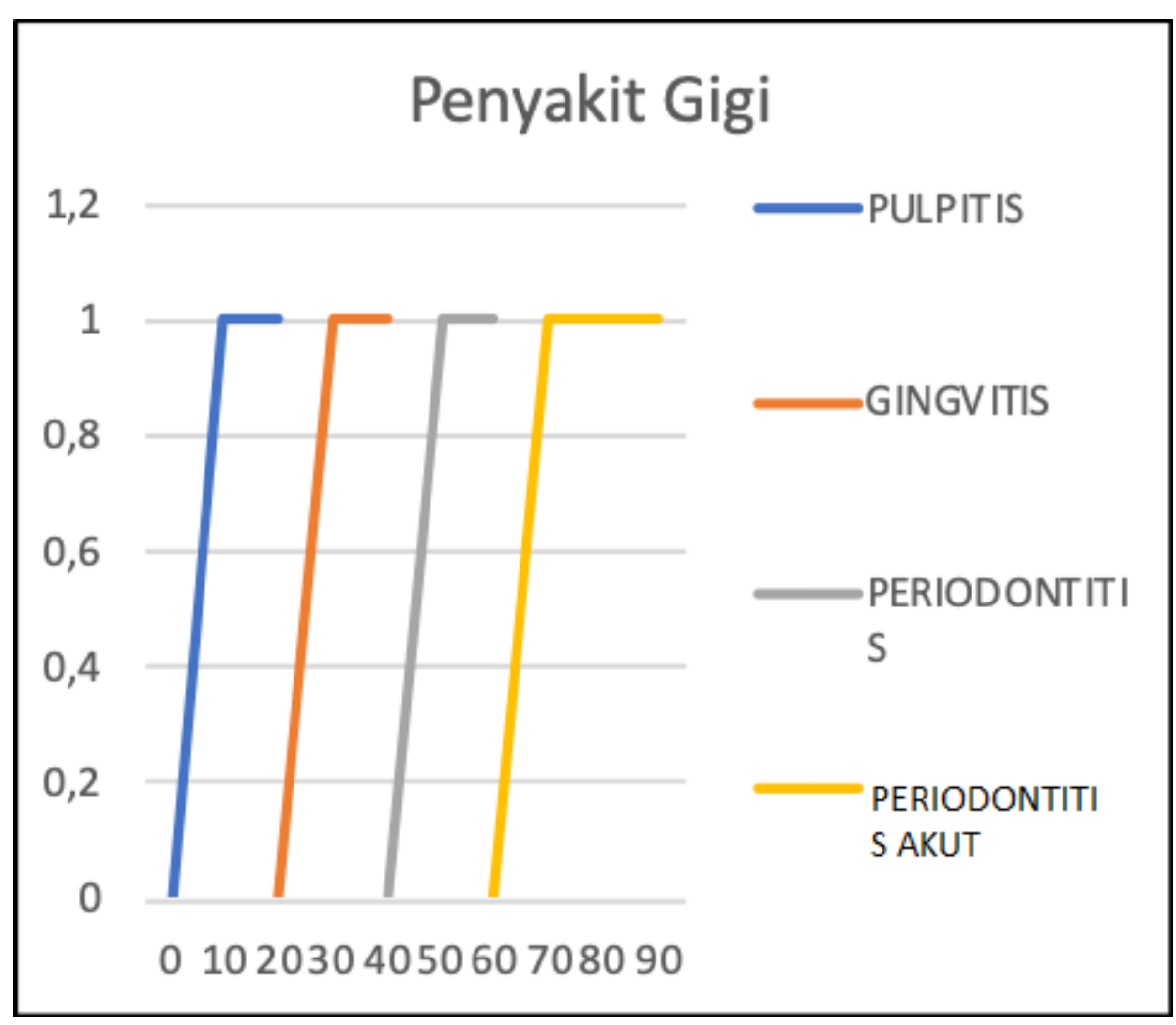

Gambar 2. Fungsi Keanggotaan Penyakit Gigi

Gambar 2 adalah fungsi keanggotaan penyakit gigi. Pada gambar ini dapat dilihat bagaimana grafik pulpitis, gingivitis, periodontitis, dan periodontitis akut. Definisi fungsi keanggotaan penyakit gigi dapat dilihat pada (4), (5), (6), dan (7).

$$
\begin{aligned}
& \mu_{A}(x)=\left\{\begin{array}{cc}
0, & x \leq 0 \\
\frac{x-0}{20-0}, & 0<x<20 \\
1, & x \geq 20
\end{array}\right. \\
& \mu_{B}(x)=\left\{\begin{array}{cc}
0, & x \leq 20 \\
\frac{x-20}{40-20}, & 20<x<40 \\
1, & x \geq 40
\end{array}\right.
\end{aligned}
$$




$$
\begin{aligned}
& \mu_{C}(x)=\left\{\begin{array}{cc}
0, & x \leq 40 \\
\frac{x-40}{60-40}, & 40<x<60 \\
1, & x \geq 60
\end{array}\right. \\
& \mu_{D}(x)=\left\{\begin{array}{cc}
0, & x \leq 60 \\
\frac{x-60}{90-60}, & 60<x<90 \\
1, & x \geq 90
\end{array}\right.
\end{aligned}
$$

Gambar 2 adalah fungsi keanggotaan penyakit gigi. Pada gambar ini dapat dilihat bagaimana grafik pulpitis, gingivitis, periodontitis, dan periodontitis akut. Definisi fungsi keanggotaan penyakit gigi dapat dilihat pada (4), (5), (6), dan (7).

\subsection{Simulated Annealing}

Simulated Annealing (SA) adalah algoritma yang bekerja untuk mengoptimalkan menggunakan prinsip-prinsip termodinamika statistik [8]. SA bekerja berdasarkan analogi proses pendinginan dan pembekuan logam menjadi struktur kristal menggunakan energi minimum yang disebut proses annealing [9].

Algoritma SA memiliki keunggulan dibandingkan algoritma metaheuristik lainnya seperti Algoritma Genetika dan Strategi Evolusi. Kelebihan SA lebih sedikit memakan waktu dalam komputasi dan lebih sedikit memori yang digunakan [10]. Algoritma SA memungkinkan solusi saat ini untuk digantikan oleh solusi tetangga terburuk dengan kemungkinan sangat kecil untuk menghindari terjebak pada solusi optimal lokal [11]. Kelemahan dalam SA adalah bahwa tidak ada jaminan untuk mendapatkan solusi yang optimal, solusi yang diperoleh untuk setiap iterasi tidak dapat direproduksi dan berbeda setiap proses karena stokastik dan relatif lambat dalam perhitungan dibandingkan dengan algoritma pencarian langsung [12]. Pencarian langsung adalah metode yang digunakan untuk menyelesaikan masalah optimasi yang tidak memerlukan informasi tentang gradien fungsi tujuan.

Tahapan dalam Simulated Annealing adalah sebagai berikut [13]:

a. Membangkitkan solusi awal $(S)$, suhu awal $T_{0}$, suhu akhir $T_{t}$, iterasi maksimum, laju penurunan suhu $\alpha$ (biasanya bernilai 0.9 atau 0.95 ), energi awal $E$, solusi terbaik $S_{\text {best }}=S$, dan energi terbaik $E_{\text {best }}=E$.

b. Membangkitkan solusi tetangga $\left(S_{n}\right)$ dan menghitung energi $E_{n}$.

c. Apabila nilai $E_{n}<E$, menuju langkah 7. Apabila tidak, menuju langkah 4 .

d. Menghitung perubahan energi $\Delta E=E_{n}-E$.

e. Membangkitkan nilai acak antara 0 hingga 1.

f. Apabila nilai $u<e^{\left(\frac{-\Delta E}{T}\right)}$, menuju ke langkah 7. Apabila tidak, menuju langkah 10.

g. Menerima solusi $S_{n}$ sebagai $S$ dan energi $E_{n}$ sebagai $E$.

h. Apabila nilai $E_{n}<E_{\text {best, }}$ menuju langkah 9. Apabila tidak, menuju langkah 10. 
i. Menerima solusi baru sebagai solusi terbaik, $S_{b e s t}=S_{n}$ dan $E_{b e s t}=E_{n}$.

j. Apabila jumlah iterasi maksimum untuk suhu saat ini tercapai, menuju langkah 11. Apabila tidak, menuju langkah 2.

k. Mengurangi suhu $T=T_{0} \times \alpha$ dimana $\alpha$ adalah laju penurunan suhu.

l. Apabila suhu minimal sudah tercapai, menuju langkah 13. Apabila tidak, menuju langkah 2.

m. Proses selesai, solusi ditemukan

\subsection{Simulated Annealing Pada FIS Tsukamoto}

Proses Simulated Annealing digunakan untuk mengoptimasi fungsi keanggotaan pada FIS Tsukamoto. Untuk mengetahui seberapa bagus hasil optimasi tersebut maka digunakan metode FIS Tsukamoto. Berikut ini tahapan dari FIS Tsukamoto
a. Hitung alpha predikat setiap aturan
b. Hitung z predikat setiap aturan
c. Kalikan hasil alpha predikat dengan z predikat dari setuap aturan kemudian dibagi dengan jumlah keseluruhan nilai alpha predikat
d. Dapatkan hasil berdasarkan perhitungan

\section{HASIL DAN PEMBAHASAN}

Percobaan sebelumnya menggunakan FIS Tsukamoto hanya mendapatkan akurasi sebesar $70 \%$. Simulated Annealing digunakan untuk mengoptimasi fungsi keanggotaan yang dimiliki penyakit gigi agar dapat meningkatkan akurasi yang dihasilkan dari algoritma FIS Tsukamoto

Setiap pengujian, masing-masing parameter akan diuji sebanyak sepuluh kali kemudian diambil rata-rata akurasi. Pengujian pertama menggunakan pengujian temperatur. Pada pengujian ini digunakan untuk melihat pada kombinasi temperatur berapa Simulated Annealing menghasilkan akurasi terbaik.

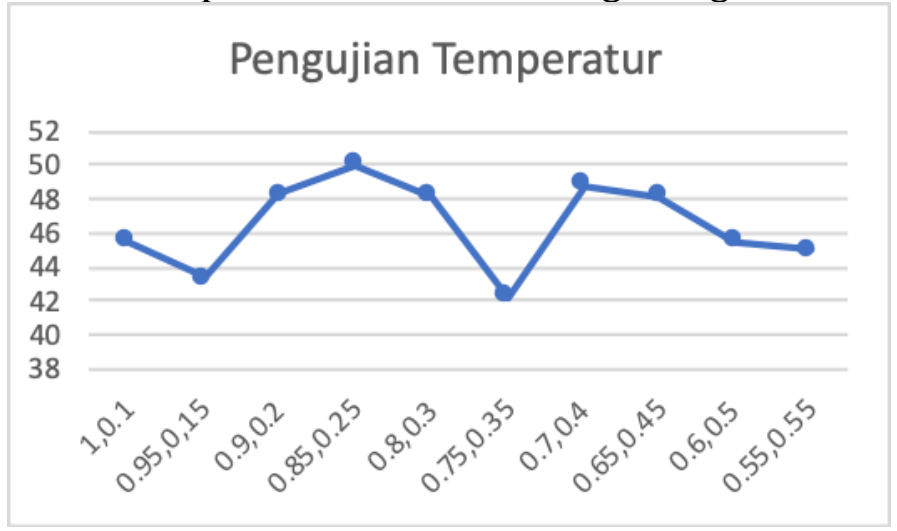

Gambar 3. Pengujian Temperatur

Berdasarkan Gambar 3 dapat dilihat untuk akurasi rata-rata terbaik sebesar $50 \%$ pada kombinasi temperatur awal 0.85 dan temperatur akhir 0.25. Pada 
pengujian ini semua parameter temperatur menggunakan nilai cooling factor sebesar 0.5 dan K sebesar 1000.

Pengujian selanjutnya yaitu pengujian cooling factor. Pada pengujian ini untuk melihat pengujian laju pendinginan pada proses Simulated Annealing.

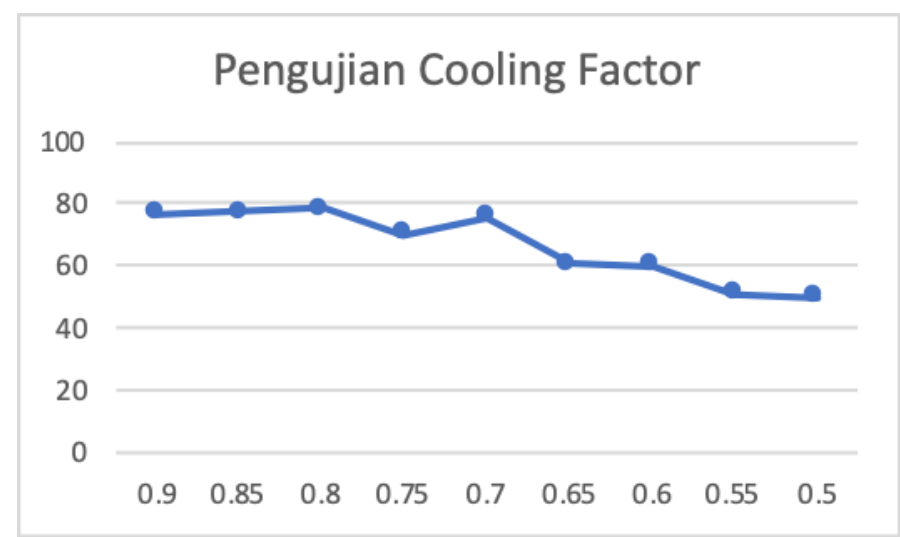

Gambar 4. Pengujian Cooling Factor

Berdasarkan Gambar 4, nilai rata-rata akurasi maksimal didapat pada nilai cooling factor 0.8 dengan akurasi sebesar $78.3 \%$. Pada pengujian ini menggunakan parameter temperatur dengan kombinasi 0.85 dan 0.25 berdasarkan parameter terbaik pada pengujian sebelumnya dan K sebesar 1000.

Pengujian selanjutnya yaitu pengujian nilai K. Pada pengujian ini digunakan untuk melihat seberapa bagus jumlah K yang digunakan untuk mengetahui akurasi terbaik. Pada Gambar 6 dapat dilihat grafik hasil akurasi pengujian nilai K.

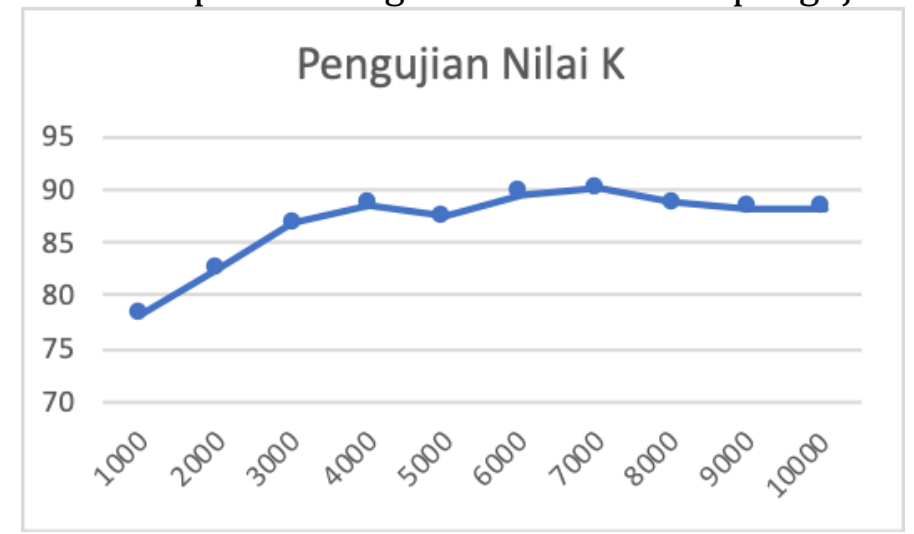

Gambar 6. Pengujian Nilai K

Pada Gambar 6 dapat dilihat grafik akurasi dari pengujian nilai K. Nilai K terbaik didapat pada K sama dengan 7000 dengan akurasi rata-rata maksimal 90.1 $\%$. Pengujian ini menggunakan parameter temperatur dan cooling factor terbaik sebelumnya. Pada pengujian ini didapat akurasi maksimal terbaik sebesar 92.5\%.

Pada Tabel 2 dapat dilihat perbandingan hasil FIS Tsukamoto yang sudah dioptimasi berdasarkan penelitian sebelumnya. 


\begin{tabular}{cccc}
\hline NO & Metode & $\begin{array}{c}\text { Rata-rata } \\
\text { Terbaik }\end{array}$ & $\begin{array}{c}\text { Maksimal } \\
\text { Terbaik }\end{array}$ \\
\hline 1 & GA-FIS [14] & 83.8 & 89 \\
2 & PSO-FIS [15] & 88 & 88 \\
3 & SA-FIS & 90.1 & 92.5 \\
\hline
\end{tabular}

Tabel 2. Perbandingan Akurasi Berdasarkan Penelitian Sebelumnya

Berdasarkan Tabel 2, SA-FIS Tsukamoto mendapatkan rata-rata terbaik dibandingkan dengan penelitian sebelumnya yang menggunakan optimasi. SA-FIS juga memberikan hasil yang lebih baik dalam memberikan akurasi maksimal dibanding metode lainnya. Selain itu SA-FIS memberikan waktu yang lebih cepat dibanding metode lain karena proses kerja yang dilakukan oleh Simulated Annealing.

\section{SIMPULAN}

Berdasarkan hasil pengujian, dapat disimpulkan parameter terbaik untuk mendapatkan akurasi rata-rata terbaik pada SA-FIS Tsukamoto yaitu kombinasi temperatur 0.85 dan 0.25 , cooling factor 0.8 , dan nilai K sebesar 7000 . Parameterparameter ini bisa menghasilkan nilai akurasi rata-rata terbaik sebesar $90.1 \%$ dan akurasi maksimal terbaik sebesar $92.5 \%$.

Berdasarkan hasil penelitian ini, dapat disimpulkan metode ini bisa menghasilkan akurasi yang lebih baik dibandingkan penelitian sebelumnya. Untuk penelitian selanjutnya, bisa menggunakan metode klasifikasi seperti Fuzzy KNN[16], Fuzzy Neural Network[7], [17] ataupun Extreme Learning Machine[18][20] untuk mendapatkan akurasi yang lebih baik lagi.

Untuk kedepannya, diharapkan bisa menghasilkan keputusan yang cepat dengan akurasi yang tinggi agar bisa diaplikasikan ke kehidupan nyata.

\section{DAFTAR PUSTAKA}

[1] R. A. Priyono and K. Surendro, "Nutritional Needs Recommendation Based on Fuzzy Logic," Procedia Technol., vol. 11, no. Iceei, pp. 1244-1251, 2013.

[2] M. Asadi, "Journal of Rock Mechanics and Geotechnical Engineering Optimized Mamdani fuzzy models for predicting the strength of intact rocks and anisotropic rock masses," J. Rock Mech. Geotech. Eng., vol. 8, no. 2, pp. 218-224, 2016.

[3] M. R. Galankashi, S. A. Helmi, and P. Hashemzahi, "Supplier selection in automobile industry: A mixed balanced scorecard - fuzzy AHP approach," Alexandria Eng. J., vol. 55, no. 1, pp. 93-100, 2016.

[4] F. Latifoglu, K. Polat, S. Kara, and S. Gu"nes, "Medical diagnosis of atherosclerosis from Carotid Artery Doppler Signals using principal component analysis ( PCA ), $\mathrm{k}$-NN based weighting pre-processing and Artificial Immune Recognition System ( AIRS )," vol. 41, pp. 15-23, 2008.

[5] A. M. A. K. Parewe, W. F. Mahmudy, F. Ramdani, and Y. P. Anggodo, "Dental Disease Identification Using Fuzzy Inference System," vol. 03, no. 01, pp. 33- 


\section{1, 2016.}

[6] A. M. A. K. Parewe and W. F. Mahmudy, "Detection of Dental Disease Using Hybrid Fuzzy Logic and Evolution Strategies," in 4th International Conference on Communication and Computer Engineering (ICOCOE), 2017.

[7] D. M. N. Fajri, T. H. Saragih, A. Hamdianah, W. F. Mahmudy, and Y. P. Anggodo, "Optimized Fuzzy Neural Network for Jatropha Curcas Plant Disease Identification," in International Conference on Sustainable Information Engineering and Technology (SIET), Batu, Indonesia, 25-25 November, 2017.

[8] S. Kirkpatrick, C. D. Gelatt, and M. P. Vecchi, "Optimization by Simulated Annealing," Science (80-. )., vol. 220, no. 4598, pp. 671-680, 1983.

[9] H. H. Örkcü, "Subset Selection in Multiple Linear Regression Models: A Hybrid of Genetic and Simulated Annealing Algorithms," Appl. Math. Comput., vol. 219, no. 23, pp. 11018-11028, 2013.

[10] T. Sousa, T. Soares, H. Morais, R. Castro, and Z. Vale, "Simulated Annealing to Handle Energy and Ancillary Services Joint Management Considering Electric Vehicles," Electr. Power Syst. Res., vol. 136, pp. 383-397, 2016.

[11] S. W. Lin and V. F. Yu, "A Simulated Annealing Heuristic for the Multiconstraint Team Orienteering Problem with Multiple Time Windows," Appl. Soft Comput., vol. 37, pp. 632-642, 2015.

[12] S. Z. Selim and K. Alsultan, "A Simulated Annealing Algorithm for the Clustering Problem," Pattern Recognit., vol. 24, no. 10, pp. 1003-1008, 1991.

[13] H. Bayram and R. Sahin, "A New Simulated Annealing Approach for Travelling Salesman Problem," Math. Comput. Appl., vol. 18, no. 3, pp. 313322, 2013.

[14] T. H. Saragih, W. F. Mahmudy, and Y. P. Anggodo, "Genetic algorithm for optimizing FIS Tsukamoto for dental disease identification," 2017 Int. Conf. Adv. Comput. Sci. Inf. Syst. ICACSIS 2017, vol. 2018-Janua, pp. 345-349, 2018.

[15] D. M. N. Fajri, W. F. Mahmudy, and Y. P. Anggodo, "Optimization of FIS Tsukamoto using particle swarm optimization for dental disease identification," 2017 Int. Conf. Adv. Comput. Sci. Inf. Syst. ICACSIS 2017, vol. 2018-Janua, pp. 261-267, 2018.

[16] T. H. Saragih, D. M. N. Fajri, and A. Rakhmandasari, "Comparative Study of Decision Tree, K-Nearest Neighbor, and Modified K-Nearest Neighbor on Jatropha Curcas Plant Disease Identification," Kinet. Game Technol. Inf. Syst. Comput. Network, Comput. Electron. Control, vol. 5, no. 1, 2020.

[17] T. H. Saragih, D. M. N. Fajri, A. Hamdianah, W. F. Mahmudy, and Y. P. Anggodo, "Jatropha Curcas Disease Identification Using Fuzzy Neural Network," in International Conference on Sustainable Information Engineering and Technology (SIET), Batu, Indonesia, 25-25 November, 2017.

[18] T. H. Saragih, D. M. N. Fajri, W. F. Mahmudy, A. L. Abadi, and Y. P. Anggodo, "Jatropha curcas disease identification with extreme learning machine," Indones. J. Electr. Eng. Comput. Sci., vol. 12, no. 2, pp. 883-888, 2018.

[19] T. H. Saragih, W. F. Mahmudy, A. L. Abadi, and Y. P. Anggodo, "Application of extreme learning machine and modified simulated annealing for jatropha 
curcas disease identification," Int. J. Adv. Soft Comput. its Appl., vol. 10, no. 2, pp. 108-119, 2018.

[20] K. V. Shihabudheen, M. Mahesh, and G. N. Pillai, "Particle swarm optimization based extreme learning neuro-fuzzy system for regression and classification," Expert Syst. Appl., vol. 92, pp. 474-484, 2018. 